\title{
Occupy Vanderbilt: uma experiência entre o ativismo social e a sociedade de controle ${ }^{1}$
}

\section{Occupy Vanderbilt: an experience between the social activism and the control society}

\author{
Pedro Torreão Sá de Almeida*
}

\begin{abstract}
Resumo: O artigo em questão tem como objetivo analisar a ocupação criada na Universidade de Vanderbilt, em Nashville, no Tennessee, na esteira dos movimentos de ocupação ocorridos no ano de 2012, tal qual o Occupy Wall Street. O estudo é feito a partir das análises sobre a questão da sociedade de controle, de Gilles Deleuze; da estruturação dos espaços através do pensamento de Marc Augé; e do pensamento sobre os movimentos sociais, de Alain Touraine. Uma análise sobre os movimentos de ocupação de praças públicas no século XXI estabelece o ponto inicial do artigo, desenvolvendo a partir daí os desdobramentos da ocupação na Universidade de Vanderbilt. Partindo desse pressuposto foi feita uma etnografia sobre o Occupy Vanderbilt, relacionando o surgimento dessa nova proposta de ativismo social e sua relação com a sociedade de controle cotidianamente presente no mundo contemporâneo.
\end{abstract}

Palavras-chave: Movimentos de ocupação. Sociedade de controle. Resistência.

\begin{abstract}
The article in question aims to analyze the occupation created at Vanderbilt University in Nashville, Tennessee, in the wake of the occupation movements in 2012, just as the Occupy Wall Street. The study is made from the analysis on the issue of control society, by Gilles Deleuze; the structuring of space through thought of Marc Augé; and the thinking of social movements, by Alain Touraine. An analysis of the occupation movements in public squares in the twenty-first century establishes the starting point of the article, developing from there the consequences of the occupation at Vanderbilt University. Based on this assumption was made an ethnography about the Occupy Vanderbilt, relating the emergence of this new proposal for social activism and its relation to the daily control of our society in the contemporary world.
\end{abstract}

Keywords: occupation movements. Control society. Resistance.

Recebido em: 30/06/2015. Aceito em: 20/04/2016.

\footnotetext{
${ }^{1}$ Estudo financiado pelo convênio CAPES/FIPSE "Making One Nation Out of Many: Multiculturalism in the United States and Brazil."

" Mestre em Sociologia pela Universidade Federal de Pernambuco. Graduado em Ciências Sociais pela Universidade Federal de Pernambuco (UFPE). E-mail: ptorreao@gmail.com.
} 


\section{Introdução}

Os anos de 2011 e 2012 foram muito produtivos quando tentamos estabelecer ressignificações do que pensamos em torno dos movimentos sociais e novas formas de reivindicação de demandas coletivas ao redor do mundo. Desde a periferia - como o Egito e a Síria - até o centro das decisões sociais - como nos Estados Unidos da América e a Espanha - houve novas formações sociais que se estabeleceram como modelos imperativos através de suas ocupações e relações com as redes sociais, por exemplo. $O$ paradigma da "revolução televisionada" mudou para uma revolução de conteúdo socialmente produzido, colocando o sujeito como centro da produção do que deve ser reverberado dentro das redes sociais atuais, mesmo aprendendo posteriormente que diversos pontos de vista geram diferentes críticas e análises sob um mesmo aspecto.

Os movimentos iniciados em primaveras, indignados e ocupantes trouxeram um novo sentido aos movimentos sociais do século XXI, que se distanciam tanto das polarizações de classe quanto de movimentos fechados em aspectos culturais próprios, há uma identificação nos dias atuais por demandas sociais coletivas feitas por grupos distintos entre si e que unem forças por um bem comum, desestabilizando formas clássicas de quebra de legitimidade através da organização de identidades coletivas múltiplas. Esse movimento chegou com peso no Brasil em meados de 2013, através de Estelitas ${ }^{2}$ e Parques Augusta ${ }^{3}$ e com toda a força da catalisação de um movimento a favor do passe livre (Movimento Passe Livre - MPL) o qual cresceu exatamente a partir dessa dificuldade do Estado em deslegitimar o

\footnotetext{
2 O Movimento Ocupe Estelita (MOE) nasceu na cidade do Recife no ano de 2012 tendo como objetivo principal a crítica da especulação imobiliária na cidade, tendo como símbolo o Cais José Estelita, área central da cidade que foi leiloada e adquirida pelo consórcio Novo Recife com o intuito de construir torres residenciais e empresariais no local. O movimento continua ativo mesmo após ocupações e reintegrações de posse no ano de 2014 (ROCHA, 2015).

${ }^{3}$ O Organismo Parque Augusta (OPA), ocorrido na cidade de São Paulo, tinha como objetivo principal barrar a construções de prédios na área do parque, que se localiza na região central da cidade. Tal movimento fez parte de uma grande luta jurídica pela preservação de uma rara área verde na região. (FOLHA DE SÃO PAULO, 2013)
}

movimento, usando a força policial e sua violência de maneira indiscriminada.

Tais configurações foram sentidas também nos Estados Unidos da América, através de seus Occupies que se alastraram por estados, cidades e universidades de todo o país, tendo como centro catalisador o Occupy Wall Street e, do mesmo jeito que no Brasil e restante do mundo, na violência policial indiscriminada, causando diversas prisões, por exemplo.

O centro de nossa análise está no Occupy Vanderbilt, movimento estudantil que uniu os estudantes a partir de três causas principais: o fim do investimento da universidade em empresas que estavam relacionadas as tomadas de terras (land grabs) na África, especialmente em Moçambique; uma maior voz e participação dos alunos nas tomadas de decisões; e por último, uma luta por melhoria salarial e estabilidade dos funcionários responsáveis pela alimentação na universidade. A organização de um movimento desse porte em uma universidade de elite nos EUA não é fácil, procurei analisar, assim, as relações entre um microcosmo de sociedade de controle presente no ambiente universitário e sua tentativa de subversão por parte do alunado.

$\mathrm{O}$ artigo se divide assim em três partes principais: primeiramente a análise dos movimentos de ocupação do século XXI; uma breve etnografia do Occupy Vanderbilt; e a análise do movimento em relação a uma teoria da sociedade de controle.

\section{Primavera global: formação dos novos movimentos sociais}

É interessante perceber que a crise instaurada no ano de 2008 nos EUA, tendo como motivos principais a bolha imobiliária, a crise e falência de bancos de investimentos tidos como tradicionais globalmente, sendo o exemplo central o Lehman Brothers, e de seguradoras como a American International Group (AIG) reverberou por todo o globo até voltar para o centro inicial, Wall Street, reduto financeiro de Nova lorque.

Os efeitos da crise financeira, que teve como epicentro os EUA, ressoaram em outros países como em um efeito dominó. A ideologia TINA ${ }^{4}$

\footnotetext{
${ }^{4}$ There Is No Alternative, ou em português, Não Há Alternativa.
} 
em relação ao mercado e ao neoliberalismo, em sua face econômica, e na globalização, na sua esfera política, trouxe aos países subdesenvolvidos, como no norte do continente africano ou na américa latina, e aos países desenvolvidos, como a Espanha, um traço de necessidade de adequação ao movimento neoliberal, acarretando uma forte desigualdade social e econômica dentro desses países, em especial os que eram liderados por ditaduras, como o Egito e Líbia.

Nos países do norte da África, especificamente, a queda na negociação de commodities, necessárias para o funcionamento econômico do país, aliado a aumento de impostos para serviços básicos, como energia elétrica, e um descontentamento político generalizado trouxe à tona o debate sobre a necessidade da superação de obstáculos e a construção de uma nova dinâmica econômica e política para a região. Em países europeus as fortes taxas de desemprego, principalmente entre os jovens, e o questionamento sobre a função do poder político e a forma de democracia adotada, fez com que novas formas de movimentos sociais eclodissem e a busca de uma nova agenda social fosse criada como forma de barrar a polarização do poder, países como Espanha, Portugal e Grécia foram centros de debate nesse sentido. A América do Sul também participou do movimento através da crise neoliberal ocorrida no Chile, no qual estudantes foram às ruas exigindo o acesso à educação pública de qualidade.

A crise econômica de dimensões globais trouxe como efeito algo inesperado inicialmente: mais do que a formação de movimentos sociais, houve um debate global em torno de termos como democracia e capitalismo financeiro, temas entendidos como fora de debate desde a superação do bloco soviético e fim das utopias, ou como diria o economista político americano Francis Fukuyama, o "fim da história" ${ }^{\text {. Talvez, }}$ pela primeira vez, houve uma ação prática em torno do objetivo real da superação da "nova

\footnotetext{
${ }^{5} \mathrm{O}$ cientista político Francis Fukuyama escreveu uma tese fundada na ideia de que com a derrocada da União Soviética e a emergência de movimentos reformistas do leste europeu existiria o processo de fim da história, no sentido hegeliano, pelo processo de estabelecimento de uma potência única, no caso a norte-americana.
}

ordem mundial" discursada pelo presidente dos EUA, George Bush.

\section{Norte da África e Revoluções Democráticas}

Entender a força dos movimentos gerados no Cairo, na Praça Tahrir ${ }^{6}$, talvez seja difícil por serem tão recentes e inéditos. Tendo como objetivo central a derrubada do governo ditatorial de Hosni Mubarak, os protestos tiveram como causa uma forte inflação e nível elevado de desemprego, causados pela crise financeira que atingiu o mundo em 2008. Dentro desse contexto outros debates foram criados, como a necessidade de democracia no país.

Esse movimento em solo egípcio que, no seu auge, em 31 de janeiro de 2011, trouxe às ruas algo em torno de 2 milhões de pessoas (SOUEIF, 2011), teve forte influência dos protestos na Tunísia, ocorridos no mês anterior. $O$ processo da Revolução de Jasmim, como é conhecida a revolução da Tunísia, levou à queda do presidente Zine el-Abidine Ben Ali, no cargo desde 1987.

Movimentos parecidos aconteceram em boa parte do mundo árabe entre os anos de 2010 e 2011, trazendo assim diversas questões à tona, como a liberdade de expressão e reunião e o uso de mídias alternativas para a criação e difusão dos protestos nos países envolvidos. Ferramentas como o Facebook e o Twitter são utilizados de forma diferente e engajados na superação dessa realidade perturbadora.

As movimentações da Primavera Árabe são criadas a partir da crítica de um modelo regional, baseado em ditaduras e governos centralizadores que tolhiam as necessidades básicas dos cidadãos. A crítica a um modelo neoliberal está inclusa no debate devido ao alto grau de empobrecimento das populações e da desigualdade social construída ao longo dos anos. Entender esse fenômeno como algo ligado globalmente é necessário, uma vez que a crítica democrática é dada em diversos níveis e em diversas localidades ao longo desse período.

\footnotetext{
${ }^{6}$ Tahrir em árabe significa libertação, tendo a praça sido rebatiza-
} da após a revolução republicana do Egito em 1952. 


\section{Mediterrâneo Europeu: Espanha, Grécia e Portugal}

Os movimentos árabes iniciados no ano de 2010 e durante o ano de 2011 exerceram forte influência no mediterrâneo europeu, tendo sido particularmente importante na Espanha com o Movimento dos Indignados, também conhecido pelo nome de 15-M. Este movimento teve influência direta nas movimentações ocorridas nos EUA e nas suas futuras ocupações.

Os protestos espanhóis, iniciados em 15 de maio de 2011, tiveram como influência os levantes acontecidos em Portugal em março do mesmo ano, conhecidos como Geração à Rasca ${ }^{7}$, que foi criado sem a participação de partidos políticos ou sindicatos e organizados via Facebook; a crise econômica e as medidas de austeridade levaram os jovens portugueses às ruas. Foi a maior movimentação social em Portugal desde a Revolução dos Cravos, em 1974, a qual reestabeleceu a democracia no país.

O movimento espanhol teve como um de seus pontos centrais a questão da crítica ao modelo democrático estabelecido, sendo uma desaprovação à tomada de decisões centralizada nos políticos e seus respectivos partidos. $O$ lema estabelecido durante os protestos foi o de "¡Democracia Real YA?" , estabelecendo assim uma crise de legitimidade do sistema político espanhol e tendo como demanda uma democracia baseada em preceitos populares, na qual os cidadãos tenham voz nas decisões políticas para além do voto.

Os atos públicos, em especial na Praça Puerto del Sol, em Madrid, levou em torno de 50.000 espanhóis as ruas (ALCAIDE, 2011). A ocupação de espaços públicos como forma de protesto se estabelece como pedra de toque das novas manifestações sociais no início da década.

Influenciados pelos protestos na Espanha, um movimento parecido aconteceu na Grécia dez dias depois. Enquanto medidas de austeridade fiscal foram sendo tomadas pelo governo grego, diversos manifestantes foram às ruas protestar contra as mesmas e a favor de uma maior participação popular nas decisões políticas. Os

\footnotetext{
${ }^{7}$ Geração Precária, em português brasileiro.

${ }^{8}$ Em português, Democracia Real JÁ!
}

movimentos tiveram como centro de protesto o parlamento grego e a Praça Syntagma. É importante lembrar as diversas greves, inclusive gerais, que tiveram lugar desde o ano de 2010 contra as decisões do governo grego.

É importante perceber que no caso europeu há uma forte influência de um bloco econômico e fortemente monetário na construção da crise e consequentemente dos protestos realizados. Medidas monetárias nacionais não são possíveis devido a moeda única do bloco europeu, fragilizando assim economias mais vulneráveis, como as dos três países anteriormente citados. Nota-se, nesses três exemplos, uma junção de dois fatores principais na construção da insatisfação popular: o primeiro deles é uma maior participação democrática, na construção de decisões nacionais, ou seja, uma crise da legitimação política; e em segundo lugar, uma insatisfação com os caminhos econômicos traçados.

O conceito de crise democrática é de importante comparação: enquanto a Primavera Árabe é pensada a partir de conceitos como liberdade de expressão e reunião, na Europa a mesma crise é problematizada dentro de sua característica de representatividade social, ou seja, em ambos os casos o conceito de democracia extrapola o senso comum que o relaciona a questão eleitoral, existindo uma problematização do conceito e a necessidade de adequação do mesmo às demandas populares.

\section{A Revolta Estudantil no Chile e Debate na América Latina}

Em maio de 2011 estudantes chilenos, universitários e secundaristas, foram as ruas para protestar contra o sistema educacional do país, altamente privatizado desde a ditadura militar, liderada por Augusto Pinochet (1973-1990). A ausência do Estado na educação básica e a falta de investimento público nas universidades foram os fatores centrais das revoltas ocorridas.

Dois elementos determinaram forte influência no movimento chileno, em primeiro lugar a conhecida Revolução dos Pinguins, movimento social criado por estudantes secundaristas no país no ano de 2006; e em segundo lugar os movimentos na Espanha (15-M) e da primavera árabe. Os protestos no Chile foram acompanhados por grande repressão do Estado e foram 
prolongados até outubro de 2011. Além de passeatas, greves estudantis foram utilizadas como tática do movimento.

Podemos dizer que os movimentos sociais que foram criados entre os anos de 2010 e 2011 no mundo não foram de grandes proporções na América Latina, tendo sido o movimento chileno algo singular na região. Movimentos de ocupação ocorreram também na cidade de São Paulo, especificamente na Universidade de São Paulo (USP), devido a repressão policial e entrada da Polícia Militar no campus, em outubro de 2011. Movimentos como Ocupa Sampa, localizado no Viaduto do Chá, no centro da cidade, também foram organizados em consonância com o movimento americano Occupy Wall Street, que trataremos a seguir.

\section{Occupy Wall Street e o retorno ao lar}

A consequência crítica da crise iniciada em 2008 no centro financeiro norte-americano tem início em setembro de 2011 sob o nome de Occupy Wall Street. Esse movimento tem como característica central a ocupação de espaços públicos na cidade de Nova lorque e a pluralidade de membros e bandeiras. Desde estudantes universitários até veteranos de guerra se uniram em protesto contra o domínio do setor financeiro nos EUA em detrimento de políticas de inclusão social. Autointitulados os $99 \%$, em alusão e comparação aos $1 \%$ da elite americana que detêm $25 \%$ do produto interno bruto (PIB), travaram uma batalha contra a má distribuição de renda no país e marginalização de grande parte da população norte-americana.

A pluralidade não se resume aos membros, mas também na união de movimentos sociais em um único ato de ocupar espaços públicos. Movimentos feministas, contra a guerra, negro, estudantil, entre outros, se uniram, porém, sendo majoritariamente independentes de qualquer filiação partidária.

O movimento se inicia no dia 17 de setembro de 2011, ocupando o Zucotti Park, em Manhattan, Nova lorque, tendo seu ápice durante uma passeata sobre a Ponte do Brooklyn no dia 01 de outubro do mesmo ano, ocasionando em torno de 700 prisões (BAKER; MOYNIHAN; NIR, 2011). Em novembro do mesmo ano, especificamente no dia 15 , ocorre a desocupação forçada do Zucotti Park pela polícia da cidade de Nova lorque.

O Occupy Wall Street criou diversas novas formas de protesto e ocupação de espaços, tendo sido fruto de diversas tentativas por parte da administração da cidade de tentar minar a ocupação. Inicialmente, os membros da ocupação foram proibidos de armarem barracas para dormir, sendo somente permitido o uso de sacos de dormir e cobertores. Outro ponto de discórdia entre os membros do protesto e a administração da cidade foi o uso de autofalantes. Essa proibição fez com que se estabelecesse o chamado Microfone Humano, técnica necessária na construção e realização de assembleias gerais. O Microfone Humano é uma técnica em que o que uma pessoa fala é repetido por todos os membros para que seja ouvido por todas, necessidade essa pelo número alto de participantes no acampamento (conhecido no Brasil também pelo nome de Jogral).

O movimento de ocupação nos EUA não ficou somente centralizado na cidade de Nova lorque, mas foi rapidamente expandido por todo o país, tendo ocorrido em cidades de grande porte, como Chicago e Boston, de médio porte como Nashville e de pequeno porte, como no Occupy Bethel, cidade de pouco mais de seis mil habitantes na tundra do Alaska, em que apenas uma mulher fez um acampamento.

Para frisar a dimensão do movimento de ocupação nos EUA é importante demonstrar que os protestos não ficaram somente voltados para a área urbana e críticas gerais sobre a situação do mercado financeiro norte-americano. Ocupações locais tinham suas próprias demandas, se distinguindo umas das outras.

O exemplo central para o debate desse artigo é a formação de ocupações universitárias no país. Questões ligadas a formações e reestruturação de um movimento estudantil e fortalecimento da posição dos estudantes perante a situação do país e da própria crítica à realidade universitária local. Diversos movimentos universitários de ocupação ocorreram nos EUA entre o segundo semestre de 2011 e o primeiro semestre de 2012. Não houve, porém, uma uniformidade das universidades, nem quanto a sua caracterização como pública ou privada, nem em relação as demandas específicas, como houve no Chile, com um conteúdo programático 
geral. Universidades tradicionais privadas, como a Universidade de Duke, Harvard e Vanderbilt aderiram ao movimento, como as públicas, tendo como forte exemplo a Universidade da Califórnia (Berkeley, Davis e San Diego).

A formação do movimento de ocupação nas universidades norte-americanas tem como perspectiva central uma oposição à tradicional forma de lidar com a política universitária que reflete os moldes da política nacional, centrada em dois partidos principais. Em suma, a política estudantil tradicional nos EUA é dividida internamente nas universidades entre os Democratas e Republicanos, tendo também em certa escala a presença de libertários (denominação ligada a uma postura conservadora de estado mínimo). A ocupação de universidades traz consigo uma negação do espaço político tradicional e institucionalmente formado. Por mais que os estudantes não clamem por uma liberdade de opinião, como foi a pedra de toque da Primavera Árabe, eles lutam por uma voz mais diversificada dentro do ambiente universitário, onde questões levantadas por grupos políticos minoritários sejam levados em conta, e não somente aqueles sancionados através de espaços políticos tradicionais. Os movimentos de ocupação não negam em momento algum a participação e apoio desses espaços institucionais tradicionais, mas há um sentimento de que eles não são suficientes e, em certos momentos, representativos do corpo de alunos.

Várias formas de protesto foram utilizadas de forma mais especifica nos movimentos de ocupação universitária. Uma das mais populares são os chamados Teach-in. Essa técnica foi criada pelo antropólogo Marshall Sahlins durante os protestos contra a Guerra do Vietnã, e consiste em uma aula expositiva em um espaço público ou que tenha algum valor simbólico para a discussão. A exposição do tema e debate do mesmo gera um maior conhecimento sobre o tema e demonstra a posição política dos participantes no local. Outras formas de expressão mais gerais aos movimentos de ocupação como os Sit-in, em que os integrantes se sentam ao chão em um local de movimento para protestar, ou as passeatas e assembleias gerais que foram também utilizadas nos centros universitários.

\section{Pontos em comum entre os diversos movimentos}

Entre os anos de 2011 e 2012 pudemos perceber uma formação global de movimentos que a despeito de seus diferentes objetivos centrais comungam de diversos aspectos e formas de agir perante seus problemas regionais, que mesmo em um mundo globalizado os diferenciam. Vemos que o início do movimento surgido no norte da África tinha como grande objetivo a emancipação democrática baseada em liberdade de expressão e fim de regimes ditatoriais, enquanto na Espanha a luta centralizou-se na democracia de uma forma direta através da crítica de uma representatividade política. Os EUA e a Grécia se diferenciam de uma maneira bastante sutil no seu cerne, mesmo tendo formas de agir diferentes, enquanto a primeira age através da crítica ao mercado financeiro baseada no mercado, a segunda se opôs diretamente a escolha econômicas estabelecidas pelo centro político nacional, subjugada a política da União Europeia. Os movimentos latino-americanos se voltaram a uma crítica do Estado em relação a políticas públicas voltadas a educação.

Entretanto, podemos ver diversos pontos de convergência entre esses movimentos específicos. Inicialmente podemos perceber a formação de uma tríade, estabelecida pelo historiador Henrique Soares Carneiro, na forma de agir desses movimentos:

Em todos os países houve uma mesma forma de ação: (1) ocupações de praças, (2) uso de redes de comunicação alternativas e (3) articulações políticas que recusavam o espaço institucional tradicional. (HARVEY et al., 2012, p. 8).

Podemos, de toda forma, perceber que cada movimento devido a seu caráter próprio deu mais ênfase a um elemento ou outro, contudo, não abdicou de usar os três ao mesmo tempo. A ocupação de praças e espaços públicos teve sua maior expressão nos movimentos norte-americanos, nos quais houve a sua concretização em tempo integral. $\mathrm{O}$ uso de redes alternativas de comunicação, como o Facebook ou Twitter, teve importância central em todos os movimentos, porém, foi simbolicamente importante na Primavera Árabe devido às restrições

284 Emancipação, Ponta Grossa, 15 (2): 279-297, 2015. Disponível em <http://www.revistas2.uepg.br/index.php/emancipacao> 
de liberdade de expressão em meios convencionais nos países envolvidos. As articulações políticas inovadoras tiveram espaço privilegiado no movimento espanhol, com a formação dos Indignados (15-M) e sua ideologia alicerçada na "Democracia Real Já!", estabelecendo assim uma crítica à representatividade política local ${ }^{9}$.

Dentro da perspectiva de crise da representatividade política, o psicanalista e crítico social esloveno Slavoj Žižek tece uma relação entre a construção da vida cotidiana e compara com as novas formas de manifestação. O fim da utopia, para o pensador, não foi determinada pelo desabe da URSS, porém, com a crise de 2008 e o fim da credibilidade completa no livre mercado:

Após a terceirização do trabalho e da tortura, após as agências matrimoniais começarem a terceirizar até os nossos encontros, os manifestantes perceberam que por um longo tempo permitiram que seus compromissos políticos também fossem terceirizados - e querem-nos de volta. (HARVEY et al., 2012, p. 18).

O debate da sobre a construção da pluralidade nesses movimentos é o tema central da próxima seção, estabelecendo ponto de discussão entre a fragmentação ou não dos movimentos dentro da ocupação mais geral. A análise e também a visão da estrutura de classes e seu potencial enfrentamento durante esses casos. O sociólogo Giovanni Alves descreve esses movimentos como uma "contingente crítica radical do capitalismo como modo de produção da vida social" (HARVEY et al., 2012, p. 36), mas não de forma estrutural dentro da crítica capitalista. Como encaixar o Occupy na Teoria dos

\section{Movimentos Sociais?}

Inserir o movimento Occupy dentro da teoria de movimentos sociais não é um trabalho fácil devido a três fatores fundamentais: o primeiro deles é a sua grande pluralidade interna, é um movimento composto por diversas frentes que se uniram em um determinado momento; o segundo fator é a sua extensa pulverização, como pensar um movimento que ressoou, dentro de estimativas, em 951 cidades em 82 países (THE GUARDIAN, 2011)? A terceira questão é relativa

\footnotetext{
${ }^{9}$ Movimento esse que culminou com a criação do Partido Podemos, na Espanha, buscando uma nova forma de representatividade e disputando eleições majoritárias.
}

ao quão recente o movimento é iniciado no segundo semestre de 2011.

\section{Occupy e pluralidade}

A fragmentação de movimentos sociais através da ótica cultural foi a pedra de toque. O movimento Occupy une esta característica ao processo de globalização desses movimentos dentro de uma perspectiva diferente: de crítica a sociedade capitalista geral, baseada em preceitos mercadológicos e de crítica a democracia tradicional.

A quebra do Estado-nação como entendido de maneira clássica é o grande campo de batalha desse movimento. A sociedade da informação e o crescimento de redes sociais possibilitam essa manifestação coletiva e baseada dentro de um preceito multicultural:

Neste cenário, os conflitos e as lutas deslocam-se de problemas internos dos Estadosnação para as estratégias transnacionais das redes financeiras. Surgem os movimentos anti e alterglobalização, que lutam contra a direção da economia na sociedade, economia esta que gera desemprego e caos urbano tanto nos países em desenvolvimento como nos desenvolvidos, em virtude dos novos conflitos dos imigrantes em face das novas políticas sociais. (GOHN, 2010, p. 117).

A pluralidade do movimento Occupy, que abrange desde os movimentos estudantis até os movimentos de classe, baseados em sindicatos e despossuídos, passando por movimentos de imigrantes e feministas criam uma nova estrutura, ou como mencionei anteriormente, um retorno. Essa pluralidade é essencial para o entendimento do Occupy como um movimento de crítica a orientações gerais da sociedade, descritos por Touraine como movimentos societais.

A característica de pluralidade e de crítica ao sistema geral como um todo está no âmago do movimento em questão, o próprio slogan altamente difundido - "we are the $99 \% " 10$ - expressa essa necessidade. A opressão não é percebida como algo particular a um grupo cultural ou a suas práticas, mas generalizado em torno da concepção de exploração financeira, baseada

\footnotetext{
${ }^{10}$ Em português: Nós somos os $99 \%$.
} 
no mercado, e na atuação do estado como mantenedor da ordem necessária para tal. Dessa forma, a união dos movimentos denota uma nova característica da atuação do grupo em relação tanto aos movimentos clássicos ou contemporâneos de análise. As diferenças são colocadas em prática de maneira sincrônica e não de maneira a serem competitivas entre si.

Seria leviano afirmar que tais junções entre movimentos não tivessem acontecido no passado. Durante a luta pelos direitos civis, na década de 1960 nos EUA, os estudantes, majoritariamente brancos e do Norte, se uniram as causas raciais do Sul em diversos momentos, como os conhecidos Freedom Riders ${ }^{11}$ ou o Freedom Summer ${ }^{12}$, porém o movimento específico de superação do capitalismo, tendo uma ampla participação de diversos setores, é de certa forma inédito nos EUA.

\section{A pluralidade e herança democrática norte- americana}

Tocqueville (2005) argumenta que a democracia norte-americana é construída em três pilares centrais: o primeiro são as comunas, observadas por ele na Nova Inglaterra, que são poderes locais organizados com leis próprias em relação ao estado e a federação; a segunda são as associações cívicas, nas quais os cidadãos se associam para fins diversos, sendo eles econômicos, políticos, sociais e etc.; a terceira é o espírito da religião como fundador moral e social, uma experiência contemporânea são as igrejas como fomentadoras na luta e organização dos movimentos de direitos civis na década de 1960, Dr. Martin Luther King Jr. é um exemplo prático como Pastor evangélico na luta.

No caso específico do Occupy o segundo fator é o mais decisivo para sua pluralidade. Uma cultura política baseada em comunas e religião são facilitadoras também, porém, as associações civis mostram a capacidade de organização.

\footnotetext{
${ }^{11}$ Movimento contra a segregação racial em ônibus, restaurantes e salas de espera de terminais rodoviários em que estudantes se dirigiam do norte ao sul dos EUA utilizando assentos e espaços proibidos a sua cor. O movimento gerou ataques em cidades do sul como Anniston, Birmingham e Montgomery.

${ }^{12}$ Movimentos estudantis a favor dos direitos ao voto dos negros em estados do sul dos EUA. Estudantes de universidades do norte foram ao sul em campanha pelo cadastramento de negros para a votação.
}

É fundamental expor, porém, que no século XX muitas associações civis nos EUA foram perseguidas, como sindicatos e partidos políticos. Porém, existe uma grande cultura de movimentos chamados de grassroots, movimentos de base, focados em políticas de uma comunidade. Esses movimentos acabam por abastecer, de certa maneira, movimentos maiores, como o Occupy.

A formação da democracia norte-americana é facilitadora de um grande movimento plural baseado na construção coletiva.

\section{Ocupação e a tomada da cidade}

Nesse ponto discutiremos o que há de novo na questão da ocupação de ambientes púbicos dentro do movimento. O que de fato ele traz de novo como tática e forma de construção e crítica da sociedade capitalista atual, através de categorias como território e urbanidade no século XXI.

A formação de ocupações não é novidade dentro dos movimentos sociais contemporâneos, muito ao contrário, existem grupos, em especial em países subdesenvolvidos, que utilizam esse método de protesto de obtenção de direitos há muito mais tempo e de maneira muito mais sistemática, e se assim podemos dizer, de maneira mais bem-sucedida.

O Movimento dos Trabalhadores Rurais Sem Terra (MST), no Brasil, e o Exército Zapatista de Libertação Nacional (EZLN), no sul do México, utilizam a ocupação como forma de luta por direitos agrários desde meados da década de 1980 , sendo o primeiro de ideologia marxista e o segundo dentro de uma lógica organizacional anarcossindicalista. A forma de pensamento dos dois grupos também não é apenas voltada para a aquisição de direitos sociais e articulação numa mudança social de nível mais geral. Porém, a organização social que ambos os grupos trazem consigo reflete um aspecto de divisão da sociedade baseada entre cidade/campo, típico de pensamentos de esquerda do século XX.

Contudo, outros movimentos também utilizam as ocupações de forma sistemática, porém no ambiente urbano. Movimentos como o Movimento dos Trabalhadores Sem Teto (MTST), no Brasil, ocupam espaços urbanos como forma de reinvindicação, logo, o que os distinguiria das mesmas formas de atuação do Occupy? Em primeiro lugar, vemos uma diferença entre os 
movimentos através da sua pluralidade, o aspecto de crítica geral do Occupy o coloca em um espaço singular; outro aspecto importante é a ocupação de espaços públicos por excelência, e não espaços privados ou sob concessão do estado. Esse exemplo se aplica da mesma forma aos movimentos de ocupação de reitorias, ocorridos no Brasil desde a década de 1960, e que teve protagonismo no movimento estudantil dos anos 2000. Ao ocupar praças públicas, literalmente, o movimento demonstra a vulnerabilidade do estado e das classes dominantes e subsequentemente do sistema financeiro, objetos da crítica geral, como afirma o geógrafo britânico David Harvey:

É de fato nas cidades que as classes ricas são mais vulneráveis, não necessariamente como pessoas, mas em termos de valor dos ativos que eles controlam. É por esta razão que o estado capitalista está se preparando para as lutas urbanas militarizadas como a linha de frente da luta de classes nos próximos anos. (HARVEY, 2012, p. 131)..$^{13}$

A questão da repressão em espaços urbanos pôde ser sentida durante a ocupação e expulsão do Occupy Wall Street no Zucotti Park, ao sul de Manhattan, Nova lorque. Fora as diversas proibições durante a ocupação, como manter barracas e o uso de megafones, a expulsão contou com a proibição da entrada de veículos de imprensa, tendo sido negada até a passagem de um helicóptero que transmitia imagens do acontecido no espaço aéreo do local. Casos como esses também aconteceram em universidades, como a Universidade da California em Davis (UCDavis), onde sprays de pimenta foram usados de maneira de forma excessiva contra estudantes sentados (CEASER, 2012).

Outro ponto central aos movimentos urbanos de ocupação é a indexação do terceiro setor, predominantemente urbano e ligado aos serviços, como agente de mudança na sociedade. Ao contrário dos movimentos clássicos, em que o proletário de fábrica é colocado como centro

\footnotetext{
${ }^{13}$ Tradução minha: "It is in fact in the cities that the wealthy classes are most vulnerable, not necessarily as persons but in terms of the value of the assets they control. It is for this reason that the capitalist state is gearing up for militarized urban struggles as the front line of class struggle in years to come." (HARVEY, 2012, p. 131)
}

revolucionário, o movimento de ocupação vê no precarizado setor um novo vetor de busca por direitos e por uma nova organização urbana.

Em segundo lugar, a urbanização é autoproduzida. Milhares de trabalhadores estão envolvidos em sua produção, e seu trabalho é produtor de valor e de mais-valia. Por que não concentrar-se, portanto, sobre a cidade em vez de a fábrica como o local principal da produção de mais-valia? A Comuna de Paris pode, então, reconceptualizar como uma luta do proletariado, que produziu a cidade para reclamar de volta o direito de ter e controlar o que haviam produzido. (HARVEY, 2012, p. 129)..$^{14}$

Vemos, portanto, na ocupação da cidade além de um questionamento de uma ordem geral baseada na não violência, a ascensão de um movimento urbano que utiliza o espaço público como forma de centralização de uma unidade, utilizando os trabalhadores precarizados do setor de serviços, fugindo ao paradigma clássico de campo/fábrica, como base de um movimento geral contra o sistema financeiro global. A ocupação urbana torna-se vetor de uma luta geral, e não somente específica ou cultural.

\section{Occupy e a ressignificação de um não lugar}

A pós-modernidade, ou supermodernidade como prefere utilizar o antropólogo francês Marc Augé, tem em sua característica a transformação de espaços públicos em não lugares. Essa categoria define uma característica de impessoalidade e transitoriedade em espaços, ou seja, a interação social é colocada de lado, as mensagens são transmitidas através de sinalizações escritas ou, quando vocalizadas, de maneira generalizada. Temos como exemplos clássicos de não lugares os metrôs, aeroportos, rodovias, salas de espera e etc.

\footnotetext{
14 Tradução minha: "Secondly, urbanization is itself produced. Thousands of workers are engaged in its production, and their work is productive of value and of surplus value. Why not focus, therefore on the city rather than the factory as the prime site of surplus value production? The Paris Commune can then be reconceptualized as a struggle of that proletariat which produced the city to claim back the right to have and control which they had produced." (HARVEY, 2012, p. 129)
} 
Espaços urbanos tem se tornado cada vez mais não lugares, o papel de transeunte nas cidades tem um aspecto de protagonismo. Oposto à característica de lar, residência, os não lugares são baseados na não personalização. Ou seja, são espaços construídos com base no uso geral, na passagem e não na personalização como algo central.

Os movimentos de ocupação tomaram esses espaços públicos como forma de reinvindicação, como forma de centralização de um debate específico, podendo assim reunir um número de pessoas em acampamentos. É interessante perceber que o acampamento de desabrigados é visto pelo autor como um não lugar, um espaço transitório em busca de um lar personalizado. Então o que distinguiria o acampamento do Occupy como um lugar?

Os campos de ocupação se inserem na categoria de Lugar Antropológico utilizado pelo autor, nela coexistem três características centrais: a identidade, a relacional e a histórica (AUGÉ, 2010). A historicidade pode ser colocada em xeque devido a sua característica recente, porém, ela pode ser validada, especialmente em espaços urbanos, como forma de oposição a construção e utilização histórica do local. A história nasce da contraposição com a utilização anterior do espaço público. O propósito da ocupação não é temporário, mas modificador, nela são construídas identidades e críticas a sociedade atual.

Reservamos o termo 'lugar antropológico' àquela construção concreta e simbólica do espaço que não poderia dar conta, somente por ela, das vicissitudes e contradições da vida pessoal, mas a qual se referem todos aqueles a quem ela designa um lugar, por mais humilde e modesto que seja. É porque toda antropologia é antropologia da antropologia dos outros, além disso, que o lugar, o lugar antropológico é simultaneamente princípio de sentido para aqueles que o habitam e princípio de inteligibilidade para quem o observa O lugar antropológico tem escala variável. (AUGÉ, 2010, p. 51).

\section{Afinal, o que é um Occupy?}

O Occupy é um movimento transnacional que utiliza das ferramentas globalizantes, como um maior acesso às mídias sociais, para tecer uma crítica a um lado descrito como opressor: o da globalização financeira. Através desse pensamento é dada a construção de uma nova forma de democracia baseada na participação em detrimento da clássica deliberação.

Ao contrário dos movimentos clássicos baseados na divisão estrutural da sociedades, seja na dicotomia proletariado/burguesia, de Marx, ou na de equilíbrio/desequilíbrio, parsoniana, e dos movimentos criados a partir da década de 1960, estabelecidos como movimentos culturais por Alain Touraine (GOHN, 2010), pela sua fragmentação em lutas próprias, o movimento Occupy é um vetor de unificação dessas lutas polarizadas na forma de crítica sistêmica do capitalismo e do mercado financeiro, como causas reais das desigualdades, vistas de maneira clara por eles após a crise dos bancos de 2008. Por ter uma posição crítica em relação ao formato da sociedade, pode ser julgado como um movimento societal.

Através de movimentos de base, grassroot movements, típicos da construção social da democracia americana, e das táticas de ocupação de espaços púbicos é criada uma ressignificação de não lugares, trazendo para esses espaços uma característica identitária, relacional e histórica, baseada na contraposição a construção e utilização social daqueles espaços.

Movimento amplamente urbano, traz à tona também o terceiro setor como formador e articulador de uma nova construção social e política. O espaço da fábrica, clássico nas lutas anticapitalistas, dá lugar à praça pública, caracterizada por sua pluralidade de pensamentos e locada no meio da cidade, no caso de Nova lorque, onde o movimento teve início, no centro financeiro mundial.

\section{Occupy Vanderbilt como resistência}

Fundada em 1857, a Universidade de Vanderbilt é localizada na cidade de Nashville, no estado do Tennessee. Conhecida mundialmente por sua tradição e excelência, sendo classificada como $15^{\mathrm{a}}$ melhor universidade nos EUA e $74^{\mathrm{a}}$ na Academic Ranking of World Universities. É a maior empregadora na cidade de Nashville, devido também a seu grande centro médico.

Dona de um respeitável fundo financeiro, no valor de 4 bilhões de dólares, a Universidade de Vanderbilt tem investimentos por todo o globo. 
Ironicamente, um desses investimentos foi a pedra de toque do início da campanha de ocupação da universidade. Juntamente com outras universidades, como a Universidade de Harvard, Vanderbilt tem investido, como se mostrou numa reportagem do jornal inglês The Guardian (2011), em empresas que promovem a desapropriação ilegal de terrenos na África, especialmente em Moçambique, forçando a expulsão de fazendeiros locais. A ausência de um guia oficial de diretrizes éticas para investimentos da universidade somou-se a mais dois fatores e viraram as principais metas do Occupy Vanderbilt, sendo os três: (1) um uso responsável do fundo de investimentos da universidade, somado a um guia de diretrizes éticas para o mesmo; (2) mais voz para os membros da comunidade nas decisões que os afetam; e (3) melhores condições para os trabalhadores da universidade, que beiram a linha de pobreza estipulada pelo governo federal americano.

A causa mais próxima e palpável utilizada pelo Occupy Vanderbilt foi a questão dos trabaIhadores, iniciada ainda em 2011 com a Living Wage Campaign ${ }^{15}$, e a consequente precarização das suas condições. Em números de 2008, a diferença de salário entre o maior e o menor dentro da universidade foi contabilizado em uma taxa de 315 para 1. Fora isto, existe uma flexibilização do trabalho a partir de contratos que estabelecem a dispensa de grande parte dos funcionários durante o período de férias de verão, colocando os mesmos em uma situação de vulnerabilidade social.

Havia no movimento desde o início uma clareza que eles não podiam se colocar como os $99 \%$, devido à alta renda dos estudantes que pagam em torno de 50 mil dólares anuais para estudarem, mas sim um senso de responsabilidade e fraternidade com a comunidade fora da universidade. O Occupy Vanderbilt começou no dia 19 de março de 2012 em um rally com aproximadamente 150 pessoas, entre elas representantes dos trabalhadores da universidade, professores e membros do Occupy Nashville. O movimento foi seguido por alguns teach-in, realizados desde antes da ocupação e protestos dentro da universidade, como forma de pressionar a reitoria para as demandas do movimento.

\footnotetext{
${ }^{15}$ Em português, Campanha pelo Salário Mínimo.
}

Assembleias gerais eram feitas semanalmente como forma de deliberação do movimento e reuniões diárias no acampamento como forma de organizá-lo. Filmes eram transmitidos em um telão e o acampamento acabou tornando-se um espaço para diversos professores trazerem suas aulas e discutir o movimento e questões relacionadas ao mesmo. Mais do que qualquer coisa aquele ambiente virou um espaço livre de debate e articulação política fora do paradigma tradicional, negando categorias como liderança, partidos políticos e representatividade tradicional, tentando suas deliberações através de uma democracia direta.

O Occupy Vanderbilt se encerrou no dia 3 de maio com a chegada das férias de verão e esvaziamento da universidade, mas trouxe um maior diálogo entre partes que pouco se comunicavam politicamente na universidade, alunos e trabalhadores.

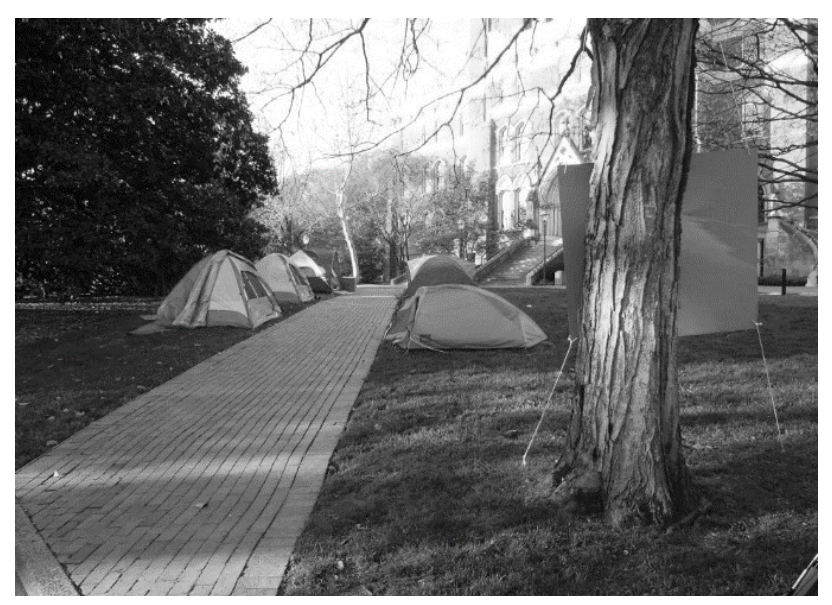

\section{A ressignificação do não-lugar na Vanderbilt}

O Occupy Vanderbilt, movimento ao qual acompanhei de perto, é um típico caso de não lugar ressignificado. A localização do acampamento foi escolhida na frente do Kirkland Hall, prédio administrativo e sede do Chancellor Office, escritório da reitoria. Em frente a esse espaço havia somente um retorno em formato de "U" para carros e um pequeno gramado ao centro: este gramado virou o acampamento. Ora, a função deste gramado era meramente o preenchimento com algo para o retorno dos carros, intercalado ao meio com um pequeno corredor de pedras para os transeuntes. Era um simples espaço 
de passagem, nada mais. A partir do início do acampamento, houve uma utilização social do espaço, a criação de significado integral para o mesmo, criando identidades que se relacionavam a partir de uma construção histórica. Ali pessoas acordavam, faziam refeições, discutiam, assistiam filmes, se reuniam e dormiam. Uma construção coletiva que ia além das barracas, mas algo ligado diretamente a um movimento global e identitário. Aulas ocorriam no espaço e membros de fora da universidade começaram a frequentar o local. A necessidade de autorização para estar naquele espaço através da carteira de identificação da universidade, símbolo da impessoalidade da supermodernidade descrita por Augé (2010) e inicialmente exigida pelo controle da instituição, nunca foi pedida. A transformação em um lugar foi construída através do debate plural entre alunos, funcionários, professores e cidadãos externos ao ambiente do Occupy Vanderbilt.

\section{Entre Homeros plurais: uma breve digressão etnográfica}

A etnografia pode ser entendida na relação entre a construção do exótico no familiar e o familiar em exótico, comparado por Roberto da Matta, o primeiro como uma viagem homérica e o segundo como uma viagem xamanística, devido a sua característica de verticalidade e interioridade (NUNES, 1978). Acredito que minha experiência na Vanderbilt teve muito de uma viagem homérica, baseada em uma necessidade de familiarização de um processo exótico, uma vez que as relações de construção políticas norte-americanas, e em especial a sua relação com ambiente universitário, me soaram bastante caras a princípio.

Meu envolvimento político dentro da Universidade de Vanderbilt se construiu desde o princípio, meio que sem querer, mas de maneira bastante participativa. Estive presente desde a formação do movimento social, organizando a montagem de suas primeiras barracas e de suas primeiras assembleias deliberativas. Minha participação foi de alguma maneira tutoreada por minhas experiências passadas dentro da vida universitária no Brasil, dentro de um movimento que vem historicamente perdendo a sua representatividade social como modelo único, como no exemplo da UNE ou dos partidos políticos inseridos dentro da universidade. O movimento da Vanderbilt é bem oposto ao que acontece no nosso país, há uma estabilização de modelos políticos dentro da universidade, mas sem a garantia de uma combatividade baseada em uma horizontalidade.

Outro grande processo mediador entre a minha relação e a minha combatividade era meu status dentro do movimento, como um estrangeiro, abertamente etnógrafo e ativista político. Esses três status nem sempre se relacionam entre si de maneira orgânica, uma vez que eu tinha um curto espaço de tempo não apenas para entender o processo político dentro de uma universidade a qual eu tinha acabado de chegar, como me fazer entender através de um inglês que por melhor que fosse não facilitava que minhas mensagens fossem passadas facilmente. A etnografia também traz um contraste com o papel de ativista político: até onde é o limite de colocar suas opiniões sem que interfiram em excesso, ou pior, causem uma perda da confiança do grupo em sua relação. Eu não tive o tempo de me socializar na universidade como um todo para entender os processos e ter como traduzi-los no ambiente político. Ao contrário de Geertz (2008), que correu com a maioria para fugir de uma batida policial numa rinha de galos na sociedade balinesa e acabou por ser inserido de maneira aberta, como ainda não havia acontecido, eu "corri" com a minoria, um grupo entre trinta e cinquenta pessoas, num universo de doze mil, como forma de integração. Numa sociedade como a norte-americana, altamente difundida globalmente e que nos passa a percepção de pasteurizada, às vezes, a busca por um grupo específico e minoritário nos dá a percepção da diferença. O movimento nasce junto com minha percepção de ser diferente naquela sociedade, fato que viria a se consolidar mais dia após dia.

Após um teach in sobre as tomadas de terra patrocinadas pelos investimentos da Vanderbilt e algumas reuniões sobre a forma de ocupação e acampamento, lá fomos nós para o rally inicial, um evento que contou com a participação de mais de cem pessoas, incluindo estudantes, profissionais da universidade, professores e membros de fora da comunidade Vanderbilt. Esse contato externo tem um peso muito grande para todos. A universidade é citada pelo próprio corpo administrativo, através de e-mails, como a VandyBubble, ou Bolha-Vandy, por ser um universo a parte cravado 
no meio da cidade de Nashville, com estudantes que vem de diversas partes do país e do mundo, sendo quase que auto-suficiente, ao contrário da cidade de Nashville, tradicionalmente uma cidade conservadora e localizada no meio do Cinturão da Bíblia, área dos EUA extremamente religiosa.

Para a minha sorte, tudo que ocorria no campo era bem noticiado e divulgado, o que fez com que a cronologia dos fatos oficiais pudesse ser feita de maneira mais facilitada ao pobre projeto de antropólogo em questão. Blogs, vídeos, fotos, páginas no Facebook, Twitter e um inconveniente chat por mensagem de texto no celular me deixavam a par de tudo que acontecia no acampamento em tempo real. A minha presença também era constante, costumava fazer as refeições possíveis no local e conviver o máximo de tempo possível.

O nosso acampamento se distinguia em quase tudo da normalidade quase que pacata da Universidade de Vanderbilt. Assim como William Foote Whyte descreveu na introdução de "A Sociedade de Esquina" que o morador de High Street, uma rua elegante de Boston, ao entrar em Connerville cruzaria a fronteira entre o familiar e o desconhecido, o mesmo acontecia com o estudante normal da universidade, ao cruzar aquele acampamento: ele entrava em um terreno pouco conhecido, algo que não fazia parte do cotidiano daquela instituição.

Aos poucos, aquele local de protesto, estranho para os próprios membros inicialmente, foi se tornando algo extremamente familiar. Eram encontrados no espaço bolas de futebol, mesa de piquenique, certos ornamentos foram colocados para customizar o local, como luzes de natal. Fora o sino da torre do Kirkland Hall que tocava de hora em hora e não poderia ser parado, todo o resto foi adaptado para uma melhor forma de socialização de todos.

Algo que me impressionava no movimento era a capacidade de informação que os membros tinham do que acontecia ao redor do mundo. MST, revoltas estudantis no Chile, Zapatismo, Indignados, revoltas na Grécia, nada estava fora do radar daquelas pessoas. Esses protestos serviam como inspiração para o movimento - pensar novas formas de articulação estudantil fazia parte da agenda - tanto em conversas informais como em reuniões deliberativas. Essas reuniões, chamadas de GA (General Assembly ${ }^{16}$ ), tiveram papel central na minha crise como etnógrafo e ativista político. Dentro do movimento, meus posicionamentos foram se tornando, no final das contas, medidos, meu medo de influenciar de maneira negativa a dinâmica presente e comprometer minha etnografia teve seu ápice nesses espaços.

Como me posicionar em espaços deliberativos? Desde o início do movimento eu tive esse debate comigo de maneira frequente. $\mathrm{O}$ tradicional movimento estudantil norte-americano é bastante institucionalizado, e como toda instituição acaba fechado a debates que são criados fora do ambiente universitário e que fujam à política tradicional.

Na primeira Assembleia Geral do movimento eu tive duas surpresas: a primeira foi imediata, com a participação de uma representante do sindicato de trabalhadores de indústrias automotivas. Achei a participação algo bastante interessante para a formação do movimento e inserção do mesmo fora dos muros da universidade. Ajudei a representante, tentando fazer essa inserção e até repassando a ela um documentário do Eduardo Coutinho, Peões, sobre os metalúrgicos brasileiros. Porém veio logo após a segunda surpresa: os integrantes preferiram não manter contato oficial com o sindicato, ou qualquer representante, tendo como justificativa evitar que os alunos se assustassem com esse envolvimento. Mesmo sabendo que o papel dos sindicatos nos EUA não é bem aceito por parte da sociedade, eu fiquei um pouco em choque: como um movimento que está englobado numa questão mundial poderia evitar um contato com a sociedade como este? Pela primeira vez eu me senti um ativista social estrangeiro, um outsider naquele momento. Fazer parte daquele movimento não era apenas um momento histórico global, mas também uma conjunção da história dos movimentos sociais norte-americanos e minha própria cultura. Resolvi, correndo todos os riscos me posicionar num debate que nasceu a partir desse momento: qual o papel dos movimentos estudantis? Ter uma agenda específica da sua posição na sociedade ou interagir com outros movimentos e colocar a sociedade em

\footnotetext{
${ }^{16}$ Em português: Assembleias Gerais.
} 
perspectiva dentro da universidade? Coloquei aos companheiros de movimento minha posição clara, que o movimento estudantil não existe sem a sociedade que envolve a universidade. Mesmo sabendo que eles entendiam o que eu falava continuaram relutantes a ideia.

Outros momentos de choque cultural aconteceram durante minha passagem pelo movimento, sendo a maioria em relação à radicalização do movimento. Dois momentos foram claros para mim: o primeiro momento foi ao assistir um vídeo de protesto - muito bem organizado por sinal, com direito a interrupção de uma recepção de executivos de alimentação de universidades de todo o país (VANDERBILT, 2012) - no qual eles liam um texto, muito bem escrito, sobre as condições dos trabalhadores da universidade que recebiam abaixo da linha de pobreza dos EUA. $O$ protesto foi bem-sucedido nos seus planos, mas o que me estranhou foi a excessiva educação deles ao agradecer os executivos por terem escutado. O segundo choque foi quando surgiu a ideia de fazer um jornal com notícias falsas, imitando o original da universidade, ideia que me trazia uma perspectiva de radicalização do movimento, durante uma assembleia foi pensado formas de arrecadar o dinheiro necessário para os custos, logo eu dei a ideia de consegui-lo ao mesmo tempo da distribuição, sendo qualquer doação aceita, caso alguém quisesse contribuir. A ideia foi totalmente rejeitada, pois era proibida a arrecadação de fundos por entidades não filiadas oficialmente a universidade e porque poderia causar uma má impressão ao corpo discente. Nesse exato momento houve a reviravolta na minha etnografia, eu percebi que as regras, e por consequência o controle, estavam enraizadas não somente na administração da universidade, mas neles próprios.

Percebi que meus papéis de estrangeiro e ativista social ali me levaram a uma questão tanto de familiaridade como de exotismo: eu consegui entender seus pontos de vista muito claramente e ao mesmo tempo repensar os meus e resignificar toda aquela minha experiência com o Occupy.

\section{Sociedade de controle e Occupy Vanderbilt}

A passagem das sociedades disciplinares para as sociedades de controle é o tema central desta seção. Tentaremos pensar como os movimentos de ocupação são tomados por valores da sociedade de controle e como ao mesmo tempo tentam se sobrepor aos tais, pensando com mais especificidade o Occupy Vanderbilt, que teve como bandeira uma luta contra a inserção mercadológica transnacional da Universidade de Vanderbilt.

Pensar as caracterizações de controle social, tanto vindo da universidade, como do próprio movimento através de formações tecnológicas e pulverização do poder, em comparação com sistemas disciplinares e altamente hierárquicos. Refletir sobre os espaços de ocupação tem como objetivo a inserção de tecnologias de controle social, quanto a cartões e formas de identificação e entrada ou proibição da mesma, dentro de uma perspectiva negativa, e ao mesmo tempo pensar o uso de recursos tecnológicos como forma de libertação e voltada para uma característica central das sociedades de controle, o marketing, pensado através e uma ótica revolucionária.

Pensaremos essa sociedade de controle dentro do universo da Vanderbilt através de três conceitos principais: primeiro a mediação social através da tecnologia e não mais do sujeito; segundo, o controle como algo interno e não mais totalmente externo; e terceiro através do posicionamento mercadológico da universidade dentro de uma perspectiva transnacional e indireta, e não mais baseada em fatores nacionais e diretos.

\section{Da sociedade disciplinar à sociedade de controle}

A sociedade disciplinar é um conceito trabalhado por Foucault que tem como ponto central o controle social estabelecido através do contato direto entre os indivíduos. O exemplo central dessa sociedade são as construções panópticas, que são pensadas através do encarceramento como forma de disciplina, ao saber que está sendo vigiado 24 horas por dia, no caso de prisões. Esse conceito traduz, por consequência, a necessidade de um sujeito como forma de efetivar a disciplina, posta em prática em diversos níveis, como prisões, escolas ou hospitais. Modelo típico de 
uma sociedade moderna, trabalhada a partir de modelos hierárquicos verticalizados e tipicamente binários, estabelecidos entre quem domina e quem é dominado.

Segundo alguns teóricos, com a ascensão das sociedades pós-modernas e ainda mais com a entrada da globalização e derrocada dos Estados-nação como centros financeiros em detrimento dos blocos atuais, a perspectiva disciplinar perde espaço para a Sociedade de Controle, caracterizada por uma horizontalização, ou pulverização dos centros de poder. A sociedade de controle não necessita mais das formas clássicas atribuídas ao disciplinamento hierárquico, mas estabelece um tipo de autodisciplina, utilizando-se e de formas de controle que dispensam a necessidade de um sujeito como observador ou dotado de poderes punitivos. O uso de tecnologias como as máquinas, câmeras de vigilância ou cartões tem como objetivo central trazer ao sujeito a questão do autocontrole, ou seja, uma vigilância permanente e dotada de poder sobre o sujeito, papéis são adquiridos e desempenhados sem a necessidade da punição ou ameaça seja diretamente atribuída a um sujeito.

Dentro de uma perspectiva mais macrossocial, podemos ver a derrocada do Estado-nação no papel financeiro tradicional e a entrada da transnacionalidade como perspectiva do mercado. Os centros de poder não produzem mais, entretanto importam seus materiais ou fazem montagens com produção apenas de peças específicas. A centralidade do mercado dessas sociedades pós-modernas não está mais na materialidade, mas na imaterialidade, através do marketing e da venda de serviços e produção tecnológica ao redor do mundo. O triunfo dessa forma de mercado faz com que as barreiras nacionais percam suas fronteiras a partir de uma terceirização dos negócios a partir de fundo de investimento, por exemplo. O primeiro exemplo que podemos dar, entre a sociedade de controle e o Occupy Vanderbilt, nasce exatamente da crítica dessa terceirização das responsabilidades de investimento.

\section{Universidade de Vanderbilt entre a disciplina e o controle}

A Universidade de Vanderbilt, e sua organização interna, podem ser pensadas como uma passagem entre as duas formas de sociedade. Por ser uma universidade extremamente tradicional no país, e também de cunho elitista, são usadas diversas formas de controle e disciplina dentro dela para adequação de seus estudantes. Tentarei enumerar algumas delas a seguir.

Ao ser aceito na Universidade de Vanderbilt, o aluno no primeiro ano obrigatoriamente vive no Commons, residência estudantil na qual é dividida por casas em que residem alunos e um professor mentor, que tem como responsabilidade guiar esses alunos dentro do meio-ambiente da universidade. Vemos a partir desse caso uma forma de controle a partir da disciplina, onde esses alunos estão sujeitados, a sanções positivas ou negativas, em relação ao professor que tem o cargo de fazê-los se adaptarem ao ambiente da universidade. Esse processo de socialização é colocado como importante para que os alunos adquiram responsabilidades na passagem entre morar em casa e morar "sozinhos" na universidade.

A partir do segundo ano em diante eles moram em outros dormitórios dentro da universidade. A relação de sociedade de controle é mais clara a partir deste ponto quando o processo de confinamento observado não é mais a pedra de toque da socialização, a adaptação já está feita, viver na órbita da universidade é o próximo passo desses sujeitos. O controle através da disciplina não é mais necessário, como diria Deleuze:

Passamos de um animal a outro, da toupeira à serpente, no regime em que vivemos, mas também na nossa maneira de viver e nas nossas relações com outrem. O homem da disciplina era um produtor descontínuo de energia, mas o homem do controle é antes ondulatório, funcionando em órbita, num feixe contínuo. Por toda parte o surf já substituiu os antigos esportes. (DELEUZE, 2012, p. 4).

A formação desses estudantes é dada através dessa bifurcação entre a disciplina inicial e o controle que acontece logo após. Aliado a essa política localizada no ambiente da universidade, as forças macrossociais determinam a necessidade do estudante de se estabelecer como membros em potencial de um mercado de trabalho. O primeiro passo para essa adaptação é o entendimento do ambiente universitário como algo individualizado e com o objetivo central de 
fortalecimento e aprimoramento técnico. O espaço crítico é colocado de lado.

A entrada do estudante em movimentos sociais e organizações políticas fora do eixo oficial, mais partidarizado e credenciado oficialmente na universidade, são vistos como um desvio dentro desse espectro inicial de socialização. Contudo, formas de punição claras não podem ser feitas contra os mesmos. Porém, formas latentes como o descrédito dos mesmos perante o corpo discente é um fato claro. O controle é estabelecido pela necessidade de estar envolto dentro dessa órbita universitária, ou certas sanções extraoficiais, como a depreciação do movimento, pode ser colocada em ação.

Contudo, o Occupy Vanderbilt conseguiu se estabelecer no meio do caminho desse controle social. Uma vez que a sua superação é algo extremamente difícil - vale ressaltar que os próprios membros do movimento se perguntavam sobre os limites da sua participação - e penosa socialmente. Porém novas formas de organização social tem surgido no ambiente universitário. É importante frisar a sua necessidade dentro de uma sociedade de controle.

Uma das questões mais importantes diria respeito à inaptidão dos sindicatos: ligados, por toda sua história, à luta contra disciplinas ou nos meios de confinamento, conseguirão adaptar-se ou cederão o lugar a novas formas de resistência contra as sociedades de controle? (DELEUZE, 2012, p.6).

A superação da condição da sociedade de controle claramente não é papel do Occupy Vanderbilt, pelo seu tamanho e vínculo universitário, mas a sua inserção em movimentos sociais que visam à superação dos modelos clássicos de organização social os posiciona no caminho desse controle, tendo eles dimensão disso ou não.

\section{Occupy Vanderbilt e a crítica ao mercado.}

Um dos principais pontos da agenda de ações do Occupy Vanderbilt foi a questão da ética dentro da política de investimentos da universidade. O jornal inglês The Guardian (2011), como pôde ser visto anteriormente, denunciou casos de tomadas de terra na África, especificamente nesse caso em Moçambique, feitas através de empresas que recebem o investimento da universidade.

A crítica do movimento se centralizava dentro da ausência de uma política de ética clara em relação a investimentos financeiros, ou seja, a partir da responsabilização não somente de quem atua como fim de uma cadeia nociva globalmente, mas também por aqueles que mesmo sem tomada de decisão final acabam por financiar essas atitudes, mesmo que sendo de forma indireta. Ao colocar em xeque esse posicionamento oficial da universidade, esse grupo de estudantes está se sobrepondo a uma política do mercado de terceirização de responsabilidades e globalização feroz, ao mesmo tempo em que se diferenciam do corpo discente, focado especialmente em suas funções técnicas e tecnológicas ordinárias dentro do ambiente universitário. Através desse gatilho a crítica a uma sociedade baseada em uma organização econômica transnacional entra na agenda política do grupo.

Quanto ao mercado, é conquistado ora por especialização, ora por colonização, ora por redução dos custos de produção. Mas atualmente o capitalismo não é mais dirigido para a produção, relegada com frequência à periferia do Terceiro Mundo, mesmo sob as formas complexas do têxtil, da metalurgia ou do petróleo. É um capitalismo de sobre-produção. Não compra mais matéria-prima e já não vende produtos acabados: compra produtos acabados, ou monta peças destacadas. O que ele quer vender são serviços, e o que quer comprar são ações. (DELEUZE, 2012, p. 4).

A expansão dessa crítica pôde ser sentida através de movimentações não somente contra a universidade, mas campanhas contra grandes redes de supermercados que ressoaram no movimento de ocupação na Vanderbilt. As ações não são focadas apenas nas relações formais, tradicionais e diretas de trabalho - mesmo essas sendo alvo do grupo também, por exemplo, a campanha pelo piso salarial dos trabalhadores de refeitório da Vanderbilt -, mas também nas escoIhas mercadológicas mais fluidas, como formas de investimento e conglomerados econômicos.

Vemos nesse ponto uma oposição clara às formas de controle que atingem não somente individualmente, mas também de forma coletiva 
e sua repercussão através do planeta, e não somente local.

\section{Occupy Vanderbilt e o uso da tecnologia para controle e libertação}

O uso da tecnologia, segundo Deleuze (2012), é um dos pontos de distinção mais claros entre as sociedades disciplinar e de controle. $\mathrm{Na}$ segunda, o uso de tecnologia é essencial como forma de vigiar os indivíduos e fazer com que eles se autocontrolem. Ao contrário da sociedade disciplinar, onde o controle remetia ao confinamento, na segunda não existe uma relação com o posicionamento espacial do sujeito, mas um tracking de mensagens, pensando a comunicação como algo cotidianamente perigoso e sujeito a vigilância, digamos assim.

Há aqui uma modificação no sentido de vigilância, que passa da sociedade disciplinar à sociedade de controle. Na primeira, a ideia de vigilância remetia ao confinamento e, portanto, à situação física que caracterizava as preocupações dessa sociedade. O problema era o movimento físico dos indivíduos, seu deslocamento espacial. Vigiar era, basicamente, regular os passos das pessoas, era olhar. Com a explosão das comunicações, uma nova figura ganha força: a vigilância das mensagens, do trânsito de comunicações. (COSTA, 2004, p. 164).

Dentro do Occupy Vanderbilt nós podemos distinguir esse tipo de vigilância tecnológica em dois momentos distintos: o primeiro sendo a partir de uma vigilância individual, quando a universidade cobra dos participantes um tipo de identificação digital, em um cartão, para participar do movimento, tendo a característica de identificação clássica e também como forma de permissão para entrar em prédios da universidade (e outras funções também, como de dinheiro eletrônico dentro da universidade), por exemplo, necessário para aqueles que ocupam o acampamento para ir ao banheiro e situações semelhantes; e em segundo lugar, a vigilância digital, a partir de redes sociais, onde são organizados os atos dos eventos. Através dessas redes a universidade era capaz de saber antecipadamente os atos dos ocupantes, como assembleias gerais e protestos, altamente difundidos na internet como forma de busca da participação estudantil naqueles espaços.

Existe uma dupla caracterização dessa vigilância constante nos ambientes de ocupação. A primeira tem um lado negativo, que é um maior controle através dos meios de comunicação dos atos estudantis. Isso não é algo somente sentido nos EUA, as organizações de protestos no Brasil através de redes sociais são constantemente monitoradas por órgãos repressores. A segunda, e positiva, é uma dinamização dos movimentos sociais em rede. Seria impossível a criação dos movimentos globais de ocupação sem as redes sociais, e consequentemente elas conseguem criar vínculos entre os movimentos estabelecendo agendas comuns. Um exemplo dessa rede relacionado ao Occupy Vanderbilt foi na sua formação, onde as barracas utilizadas foram enviadas pelo Occupy Harvard.

Um ponto intrigante, contudo, é o monitoramento dentro do próprio grupo através da tecnologia. Pontos positivos e negativos podem ser misturados quando falamos dentro dessa perspectiva. Pensar que o membro está envolto em informações sobre tudo que acontece, sendo as mesmas mediadas por grupos de SMS em tempo real nos telefones, Facebook, Twitter e diversas outras ferramentas, faz com que 0 contato fique fechado a um grupo específico de interessados. A informação chega bastante direcionada, perdendo assim o embate presencial de ideias com pessoas contrárias às difundidas. Um simples apertar de botão estabelece se você quer ou não se informar sobre aquilo, perde-se assim a surpresa do cotidiano.

Porém, muita da ingenuidade nas redes sociais foi perdida, havendo a necessidade de protestos que precisam ser organizados secretamente, e geralmente são postas em prática com sucesso, o Occupy Vanderbilt, por exemplo, invadiu uma reunião de executivos de alimentação de universidades norte-americanas. Também, através das redes, é possível rastrear a agenda dos executivos da universidade e saber quando é interessante marcar presença.

\section{Conclusões}

Os acontecimentos nos EUA definitivamente não começaram em 2011, como a data cronológica dos futuros livros de história mostrará, 
mas teve início em 2008. Sequer tiveram como "maternidade" a cidade de Nova lorque, ele teve início em cada revolução acontecida pós 2008, desde as revoltas democráticas no Norte da África até a organização estudantil chilena. O povo norte-americano cedeu o palco para o que o mundo queria demonstrar fazia muito tempo. $\mathrm{O}$ descontentamento com uma economia de mercado que tem como estratégia a exclusão dos indivíduos do processo produtivo e uma democracia participativa que terceiriza a tomada de decisões. Os movimentos de ocupação, e sua reverberação global, trouxeram consigo a utilização das armas do inimigo, como a globalização desenfreada, para um fim de justiça social. As redes sociais ajudaram nesse processo, que antes de qualquer coisa é um grito democrático de uma porção de excluídos.

Encaixar essa nova forma de participação nas teorias clássicas e contemporâneas não é fácil, pois suas técnicas e formas de ação já são conhecidas, mas o seu potencial de difusão e pluralidade é algo muito novo. O movimento de ocupação une os movimentos sociais setorizados desde a década de 1970 em torno de um conteúdo principal, sem jamais haver uma perda de suas demandas. A cidade é palco dessas transformações e da tomada do espaço público como reivindicação e como direito do cidadão. $O$ uso do sociólogo Alain Touraine é importante para pensar a refragmentação desses movimentos, antes sectarizados em suas próprias causas.

A etnografia teve papel fundamental no trabalho como forma de pensar esse movimento à luz do que estava acontecendo. Menos de 6 meses depois do primeiro acampamento no Zucotti Park, em Nova lorque, eu estava dentro de uma barraca, tentando entender um movimento global que acontecia. O seu entendimento não foi fácil, ainda mais por estar em um país diferente, mas enriqueceu minha visão como cientista social tanto como forma de aprimoramento em um método, como na capacidade de poder ligar o pensamento a teoria. Escutar o anthropological blues (NUNES, 1978) é algo singular.

Á luz dos fatos da etnografia, pude traçar um perfil do Occupy Vanderbilt como um movimento que tentou parar as forças de uma sociedade de controle, ora usando as táticas do inimigo, em outros momentos esquecendo a interiorização disciplinadora ao qual os integrantes foram socializados, mas acima de tudo, indo contra uma política de mercado, se inserindo dentro de uma crítica contemporânea a sociedade que vivem. Fazer isso não é fácil e com a proximidade dos fatos, ainda é muito pouco palpável.

Concluo, assim, que os movimentos de ocupação tiveram como ponto central uma crítica ao mercado e ao sistema democrático vigente, fugindo assim dos modelos de movimentos sociais que funcionavam a partir de agendas próprias e segmentadas. O espaço da cidade pôde unir essas diferentes agendas e concentrá-las. A utilização de redes sociais, globalizando o discurso, teve papel fundamental na expansão desses movimentos por todos os continentes em busca de um objetivo: justiça social ${ }^{17}$.

\section{Referências}

ALCAIDE, Soledad. Movimiento 15-M: los ciudadanos exigen reconstruir la democracia. 2011. Disponível em: <http://politica.elpais.com/politica/2011/05/16/ actualidad/1305556621_810419.html>. Acesso em: 17 maio 2011.

AUGÉ, Marc. Não lugares: introdução a uma antropologia da supermodernidade. 9. ed. Campinas: Papirus, 2010. 111 p.

BAKER, Al; MOYNIHAN, Colin; NIR, Sarah Maslin. Police Arrest More Than $\mathbf{7 0 0}$ Protesters on Brooklyn Bridge. 2011. Disponível em: <http://cityroom.blogs. nytimes.com/2011/10/01/police-arresting-protesterson-brooklyn-bridge/>. Acesso em: 01 out. 2011.

BRYM, Robert et al. Sociologia: sua bússola para um novo mundo. São Paulo: Thomson, 2006. 585 p.

CEASER, Stephen. UC to pay nearly $\$ 1$ million in UC Davis pepper-spray settlement. 2012. Disponível em: <http://latimesblogs.latimes.com/lanow/2012/09/ucdavis-pepper-spray.html>. Acesso em: 26 set. 2012.

COSTA, Rogério da. Sociedade de Controle. São Paulo Em Perspectiva, São Paulo, v. 1, n. 18, p.161167, 2004.

\footnotetext{
${ }^{17}$ No início de 2013 foi revelado pelo The Oakland Institute, que trata de questões relacionadas a sociedade, meio ambiente e economia, que a Universidade Vanderbilt, pela primeira vez na história retirou um investimento por pressão estudantil, o documento cita que nem investimentos da universidade em empresas que apoiavam o apartheid tinha sido retiradas, anteriormente, um marco histórico para o movimento estudantil da universidade (MITTAL, 2013).
} 
DELEUZE, Gilles. Post-scriptum sobre as sociedades de controle. Disponível em:<http://www. portalgens.com.br/filosofia/textos/sociedades_de_ controle_deleuze.pdf >. Acesso em: 04 jun. 2015.

FOLHA DE SÃO PAULO (São Paulo). Moradores se mobilizam pelo Parque Augusta. 2013. Disponível em: <http://fotografia.folha.uol.com.br/galerias/18475moradores-se-mobilizam-pelo-parque-augusta> . Acesso em: 15 ago. 2013.

GERTZ, Clifford. A interpretação das culturas. Rio de Janeiro: Ltc, 2008. 215 p.

GOHN, Maria da Glória. Novas teorias dos movimentos sociais. 3. ed. São Paulo: Edições Loyola, 2010. $166 \mathrm{p}$.

GOHN, Maria da Glória. Teoria dos Movimentos Sociais: paradigmas clássicos e contemporâneos. 7. ed. São Paulo: Edições Loyola, 2008. 383 p.

HARVEY, David... et al. Occupy: movimentos de protesto que tomaram as ruas. São Paulo: Boitempo Editorial, 2012.

HARVEY, David. Rebel cities: from the right to the cities to the urban revolution. New York: Verso Books, 2012. $187 \mathrm{p}$.

INSIDE VANDY (Nashville). Occupy Vanderbilt begins. Disponível em: <http://www.insidevandy.com/ news/campus_events/article_0249c21e-72a1-11e19f2e-0019bb30f31a.html>. Acesso em: 20 mar. 2012.

MATTA, Roberto da. Ofício do etnólogo, ou como ter "Anthropological Blues". In: NUNES, Edson de Oliveira. A aventura sociológica: objetividade, paixão, improviso e método na pesquisa social. Rio de Janeiro: Zahar, 1978. p. 23-35.

MITTAL, Anuradha. Vanderbilt University Divests from "Land Grab" in Africa. Disponível em: <http:// www.oaklandinstitute.org/vanderbilt-university-divestsland-grab-africa>. Acesso em: 13 fev. 2013.

NEWS CHANNEL 5 (Nashville). Students Gather At Occupy Vanderbilt. Disponível em: <http://www. newschannel5.com/story/17195003/students-gatherat-occupy>. Acesso em: 19 mar. 2012.

ROCHA, Maria Eduarda da Mota. Ocupe Estelita e a "sociedade dos muros". 2015. Disponível em: <http://brasil.elpais.com/brasil/2015/05/25/ politica/1432560448_510212.html>. Acesso em: 25 mai. 2015.

SOUEIF, Ahdaf. Tahrir Square protests: 'For everyone here, there's no turning back'. 2011. Disponível em: <http://www.theguardian.com/world/2011/feb/01/ahdafsoueif-egypt-protests>. Acesso em: 01 fev. 2011.

THE GUARDIAN (Inglaterra). John Vidal e Claire Provost. US universities in Africa 'land grab': Institutions including Harvard and Vanderbilt reportedly use hedge funds to buy land in deals that may force farmers out. Disponível em: <http:// www.guardian.co.uk/world/2011/jun/08/us-universitiesafrica-land-grab>. Acesso em: 08 jun. 2011.

THE GUARDIAN (Inglaterra). Occupy protests around the world: full list visualised. Disponível em: <http://www.guardian.co.uk/news/datablog/2011/ oct/17/occupy-protests-world-list-map>. Acesso em: 14 nov. 2011.

TOCQUEVILLE, Alexis de. Democracia na América: Leis e Costumes. 2. ed. São Paulo: Martins Fontes, 2005. 560 p.

VANDERBILT, Occupy (Org.). Occupy Vanderbilt Interrupts Executives' Conference. 2012.

Disponível em: <https://www.youtube.com/ watch?v=f0hBDj2kdv0>. Acesso em: 22 mar. 2012. 